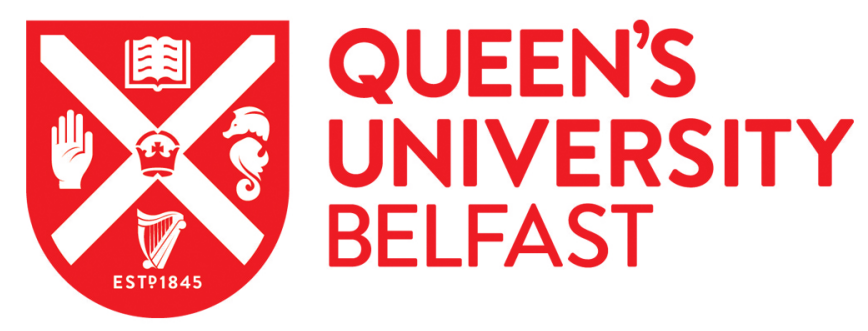

\title{
Post-conflict area-based regeneration policy in deprived urban neighbourhoods
}

Mohan, G., Longo, A., \& Kee, F. (2019). Post-conflict area-based regeneration policy in deprived urban neighbourhoods. Regional Studies. https://doi.org/10.1080/00343404.2019.1644450

\author{
Published in: \\ Regional Studies
}

Document Version:

Peer reviewed version

Queen's University Belfast - Research Portal:

Link to publication record in Queen's University Belfast Research Portal

Publisher rights

Copyright 2019 Taylor and Francis. This work is made available online in accordance with the publisher's policies. Please refer to any applicable terms of use of the publisher.

\section{General rights}

Copyright for the publications made accessible via the Queen's University Belfast Research Portal is retained by the author(s) and / or other copyright owners and it is a condition of accessing these publications that users recognise and abide by the legal requirements associated with these rights.

Take down policy

The Research Portal is Queen's institutional repository that provides access to Queen's research output. Every effort has been made to ensure that content in the Research Portal does not infringe any person's rights, or applicable UK laws. If you discover content in the Research Portal that you believe breaches copyright or violates any law, please contact openaccess@qub.ac.uk. 


\section{An evaluation of the economic effect of a post-conflict area-based regeneration policy in deprived urban neighbourhoods in Northern Ireland}

Neighbourhood Renewal is the main area-based urban regeneration initiative in Northern Ireland. The region is a unique setting for urban regeneration because of an enduring legacy of ethno-religious conflict. Using longitudinal micro data, we investigate the effect of the policy on the economic welfare of residents living in policy-on areas compared to three policy-off control groups. Difference-in-difference regression on employment and unemployment status, household income, benefit receipt and subjective financial status reveals that Neighbourhood Renewal did not close the gap in economic circumstances. However, the policy contended with a challenging economic period, which may have constrained the ability of areas to fully capitalize on the initiatives. 


\section{Introduction}

Reviving the economic fabric of deprived urban areas is a key motivation for state-sponsored urban regeneration policies. Deprived neighbourhoods are typically characterised by high rates of unemployment, low incomes, social challenges and physical decay. From a social justice perspective, area-based initiatives (ABIs) are designed to provide opportunities for individuals whose life chances are thought to be adversely affected by virtue of residing in socially excluded communities. Financial and material resources are channelled to geographically targeted areas over a specified period. These policies aim to close the gap between 'underperforming' neighbourhoods and city or nation-wide average performance.

ABIs may be theme-orientated such as enterprise, empowerment and employment zones, housing, health and education action zones or they may be more holistic in their ambitions. Holistic ABIs are those designed to address a multitude of objectives within the same policy framework including economic, social and environmental disparities. Whilst there is academic literature evaluating the effectiveness of some types of ABIs such as enterprise zones on job creation (Boarnet and Boagart, 1996; Bondonio and Engberg, 2000; Greenbaum and Engberg, 2000; O’Keefe, 2004; Neumark and Kolko, 2010; Ham et al., 2011; Busso, Gregory and Kline, 2013; What Works Centre for Local Economic Growth, 2016a), location decisions (Mayer, Mayneris and Py, 2015), European regional policy (What Works Centre for Local Economic Growth, 2016b) and economic performance (Longo and Alberini, 2006; Cizkowicz et al., 2017), evaluations of the economic impact of more holistic urban regeneration policies are sparse. Robust evidence on the economic potential of such multi-faceted ABIs is required to inform policy decisions. As such, this study contributes to an important, policy-relevant, evidence gap on the effects of such policies on the economic welfare of residents in assisted areas. 
Neighbourhood Renewal (NR), a £194 million taxpayer-funded, holistic urban regeneration policy in Northern Ireland (NI) provided an opportunity of a natural experiment. NR's principal aim was to reduce the gap in quality of life between residents of the most disaffected neighbourhoods and the rest of NI. To achieve this, NR operated over a ten-year horizon, providing development momentum for sustained coordinated investment across four interlinking objective areas (Department for Social Development 2003, p.23):

1. 'Community renewal - to develop confident communities that are able and committed to improving the quality of life in the most deprived areas of Northern Ireland

2. Economic renewal - to develop economic activity in the most deprived neighbourhoods and connect them to the wider urban economy

3. Social renewal - to improve social conditions for the people who live in the most deprived neighbourhoods through better co-ordinated public services and the creation of safer environments

4. Physical renewal - to help create attractive, safe, sustainable environments in the most deprived neighbourhoods.'

Our investigation of NR exploits secondary data from a rich longitudinal survey of residents followed for two years prior to the policy launch and for a decade of policy rollout. The twelve-year observation of individual respondents is longer than most studies in the extant literature. Respondents residing in NR intervention areas were compared with three control groups. This study provides a unique analysis of the effect of a regeneration policy on five outcomes concerning the economic welfare of respondents: employment and unemployment statuses, household income, receipt of welfare benefits and respondent's own views of their financial wellbeing. The econometric approach of difference-in-difference is used to estimate the effect of the policy on outcomes, improving upon a statutory evaluation of NR which used weaker evaluation methodology (RSM McClure Watters, 2014). 
To the authors' knowledge, it is the first study of its kind to investigate the economic effect of urban regeneration in the setting of religiously divided communities. There is some debate in NI as to whether religious background affects economic circumstances (Osborne and Cormack, 1986; Finnegan, 1998; Plöger, 2007; The Portland Trust, 2007). For example, The Portland Trust (2007, p.4) commented that 'economic disparity was a principal aggravating factor in touching off and sustaining violence. Together with a series of legislative changes, improved economic conditions helped reduce the disparity between Catholic and Protestant unemployment rates from as high as $14 \%$ in 1985 to about $3.5 \%$ in 2004'. The inquiry is original in that it explores whether the economic effect of the policy was different for different groups with the analysis stratified by gender, religion and education of respondents. The study of regeneration post-conflict is relevant for other jurisdictions which have experienced ethnic conflicts such as the Basque region (Abadie et al., 2010), Corsica, South Africa, the former Yugoslavia, Cyprus and Israel/Palestine.

The remainder of this paper is organised as follows. An overview of the literature investigating the economic effects of ABIs, with emphasis on evidence exploring holistic ABIs, is provided. The NR policy and context of NI is described. The methods used to assess the economic impact of NR are outlined, and the results presented. An interpretation of the findings is discussed along with the merits and drawbacks of the approaches employed and implications for research and practice. Overall conclusions are offered.

\section{Literature evaluating economic effects of ABI's}

Place-based or spatially targeted policies typically involve area-based initiatives (ABIs), implemented to improve outcomes in targeted, defined geographic areas over a specified period. National governments and supra-national federations such as the European Union (EU) have employed economic ABIs to improve the economic performance of relatively 
weaker regions. These economic ABIs aim to foster local economic growth by incentivising businesses to locate in designated areas, thereby hoped to create local jobs, reduce unemployment and raise incomes of residents. Economic ABIs, such as Enterprise and Empowerment Zones, may incorporate a suite of tools including tax exemptions, subsidies on wages or hiring costs, business support, discretionary grants, relief of regulations and/or investments in infrastructure. The effectiveness of economic ABIs on employment in assisted areas has been widely explored in economic literature, uncovering mixed results (Neumark and Simpson, 2015; What Works Centre for Local Economic Growth, 2016a, 2016b review the evidence). In highlighting but a few of the studies here, we note that positive effects of Enterprise Zones on local employment have been uncovered (Papke, 1994; Ham et al., 2011; Busso, Gregory and Kline, 2013; Mayer, Mayneris and Py, 2015; Cizkowicz et al., 2017), but the durability of benefits may erode over time (O’Keefe, 2004; Gobillon, Magnac and Selod, 2012; Givord, Quantin and Trevien, 2018). Alternatively, a number of other studies cast doubt on the effectiveness of enterprise zones in boosting local employment (Boarnet and Boagart, 1996; Bondonio and Engberg, 2000; Greenbaum and Engberg, 2000; Neumark and Kolko, 2010; Accetturo and de Blasio, 2012)

Regional policy of the EU aspires to advance the economic performance of poorer regions and reduce regional disparities. The various phases of the EU's Objective 1 Programme, intended to stimulate GDP per capita growth in eligible regions by means of public transfers, have been studied extensively in the literature. Objective 1 treatment from 1989-2013, was found to have positive effects for recipient region's GDP growth (Becker, Egger and von Ehrlich, 2018), but the effects were short-lived. The economic crisis weakened the effectiveness of Objective 1, particularly so for countries harder hit by the crisis. Whilst employment growth is not a stated aim of Objective 1 support, receipt of transfers was not found to support employment growth, except for the 2007-2013 period, a result also 
uncovered by Becker, Egger and von Ehrlich (2010). Alarmingly, the effects of losing Objective 1 status was deleterious to economic growth. Evaluations of the EU's Lisbon Strategy to foster economic growth and jobs also found that progress was disappointing (Raveaud, 2007; European Commission, 2010). Evidence suggests that the success of EU policies may be influenced by the quality of governance and human capital in recipient regions (Becker, Egger and Von Ehrlich, 2013).

This review now turns to look at more holistic ABIs, for which there is less evidence of economic achievements. Holistic ABIs endeavour to address a range of themes, whereby economic improvement is pursued alongside other objectives including social, environmental and community enhancement. Holistic ABIs may state that reducing unemployment in an area is a policy aim and the tools used by holistic approaches may differ from that of economic-focussed ABIs. Holistic initiatives may support enterprise development and target out-of-work residents in a community. The channels through which this is executed might include job and skills training, neighbourhood support for finding work, mentorship within the community setting, as well as financial incentives for job-seekers or employers and childcare interventions.

Few studies investigate the effect of holistic urban regeneration policies on economic outcomes for residents of areas experiencing regeneration efforts. Evaluations of economic impacts are often found in grey literature in the form of government or statutory commissioned evaluations of programmes (Tyler et al., 2007; Department for Communities and Local Government, 2010a). On the other hand, an increasing body of evidence investigates the health effects of urban regeneration, and, in this context, unemployment is considered as a relevant outcome, since it is regarded as a social determinant of health (see McCartney et al. 2017 and Thomson et al. 2006 for reviews). The New Deal for Communities (NDC) in England is a leading example of a holistic ABI. NDC has been extensively studied 
in the literature, and it is a focal policy example for this review since it most closely resembles NR in NI.

NDC was launched in 1998 as a ten-year regeneration policy targeting thirty-nine deprived communities in England. The policy was designed to improve place-based outcomes across the themes of crime, local community, housing and the physical environment, and people-based outcomes including worklessness, education and health. Different studies of NDC have led to divergent conclusions on the economic effectiveness of the policy. For the first six years of the policy, Romero and Noble (2008) found that in NDC areas claimants of worklessness benefits were more likely to exit worklessness than claimants in deprived control areas. Gender differences were also uncovered in that the effect of NDC was only observed for male Job Seekers Allowance claimants.

On completion of NDC, the government commissioned a large scale ex-post evaluation of the programme (Department for Communities and Local Government, 2010a). Evidence from cross-sectional household surveys conducted in NDC and correspondingly distressed control areas revealed that there was no change in unemployment rates, work limiting illness rates and benefit receipt in NDCs.

For a short, two-year follow-up of respondents, Romero (2009) found that NDC had mixed effects on transitions to employment. For those in full-time education or training, NDC increased the probability of entering employment. However, no significant effect was found for those claiming worklessness benefits. The results also showed that for low income groups a higher likelihood of entering employment was significant for NDC areas, indicating the policy had a redistributive effect.

Foden et al., (2010) investigated the effects of NDC on 'beneficiaries' - those who reported having heard of or used NDC projects in the 2002-2004 household surveys. Transitions into employment for beneficiaries had significantly higher odds than non- 
beneficiaries, with larger effects observed for larger projects. Beatty et al., (2010) report a three-percentage point increase in employment for NDCs in 2002-2008, compared to zero change over the same period for England, and a one percentage point increase in employment for comparator areas. By contrast, analysis of the NDC household survey for panel members who 'stayed' resident in NDC areas 2002-2008, by Wilson (2013) did not uncover net additional effects of the policy on worklessness and household finances.

Stafford et al. (2014) exploited the repeated cross-sectional NDC household survey to evaluate the impact of NDC on health inequalities. Employment was considered as a social determinant of health. In the NDC areas the likelihood of not being in paid employment was significantly higher than in the least deprived comparator areas. However, the gap between NDC areas and the least deprived areas in terms of the proportion in paid employment did not narrow over time, rather a non-significant widening of the gap was observed.

Overall, therefore, the evidence is mixed as to the economic impact of ABIs and where an effect is observed it is often context-specific. The mixed findings may be attributable, in part, to variation in the methods used. Empirical holistic studies are few and scattered across a broad geography, requiring additional nuance to their interpretation and generalisability. The current study advances the literature on the economic effect of holistic urban regeneration in the distinctive socio-political environment of NI, a region recovering from sectarian strife.

\section{Neighbourhood Renewal in Northern Ireland}

The NR Strategy was designed to provide concentrated investment to rehabilitate a selection of NI's most disadvantaged communities. The setting for regeneration efforts in NI is complex as a result of a legacy of thirty years of sectarian civil unrest and political division, a period known as 'The Troubles', dating 1968-1998. At the heart of the conflict lay a 
territorial dispute over the constitutional status of NI, originating from the partition of Ireland in 1921. The majority Protestant population of NI identified as unionists and wanted to remain part of the UK, while nationalist republicans, mainly the minority Catholic population, wanted to achieve a united Ireland. Violence between the communities began with clashes during civil rights demonstrations of the late 1960s, when Catholics challenged inequality and discrimination they experienced in employment, housing and political representation under unionist governance (Whyte, 1983; Breen, 2000).

During thirty years of conflict, over 3,600 people were killed (McKittrick et al., 1999) and the NI economy experienced high levels of unemployment, an absence of inward investment and a brain drain of educated young people (Cairns and Darby, 1998). The Good Friday Agreement of 1998, a political arrangement for a power-sharing government in NI marked the end of The Troubles and facilitated the peace process. However, for the most marginalised areas that were at the centre of the conflict, the promise of economic regeneration by means of a 'peace dividend' has not been realised (O'Hearn, 2000, 2008; Coulter, 2014; Knox, 2016). Worklessness, and a lack of enterprise and private sector investment, remained a pervasive feature in the socio-economic landscape of marginalised areas (Adair, Berry and McGreal, 1996; O’Hearn, 2000, 2008).

The NR policy selected thirty-six regeneration areas, which were the top ten-percent most deprived urban wards according to the 2001 Noble Deprivation Measure (further details on the selection of areas is provided in the Supplementary File). In the capital city of Belfast, fifteen NR areas (NRAs) were established, four in the city of Derry/Londonderry and a further seventeen were scattered across towns and cities throughout NI. In 2001, $16.5 \%$ of the NI population lived in NRAs (approximately 278,000 persons). Each NRA had a partnership board made up of stakeholders including representatives from statutory and delivery bodies, community groups with resident participation. NR Partnerships outlined priorities for NR 
investment to address local needs.

The economic renewal theme supported funding of business accommodation to provide employment opportunities and services in the NRAs, training, labour market engagement activities, social economy and business development. The NR projects and resources were designed to complement mainstream provision of public employment and welfare services. Annual reports emphasised that NR-sponsored employment, skills and enterprise projects targeted and achieved reach among 'hard-to reach' groups.

NR provided for the largest government-backed financial support available to the selected underprivileged neighbourhoods in NI. From 2003/04 to 2012/13, £194 million was defrayed under the policy. The average annual per capita spend was $£ 75$ for residents of NRAs. However, the proportions allocated against each renewal theme were undocumented due to a lack of monitoring of the policy in the early years of its deployment. Eight years after the policy launch, the mid-term review recommended that NRAs produce yearly reports detailing activities, outputs and expenditures (Department for Social Development, 2011). The economic renewal theme attracted $9.1 \%$ of the NR budget in $2012 / 13$, with wide variations in economic expenditures across NRAs (Department for Communities and Neighbourhood Renewal Partnerships, 2013).

A final evaluation of NR, commissioned to an external consultancy compared percentage point changes in available administrative statistics over the programme period (RSM McClure Watters, 2014). The comparison was simply between NRAs and all policyoff areas in NI, non-NRAs. Since NRAs represented the most deprived urban areas in the country, the comparison of NRAs with the rest of the country, did not compare 'like with like'. The evaluators concluded that significant progress under economic renewal was not realised (summarised in Supplementary Table S-1). The analysis did not control for 
characteristics of the population and because of the risk of confounding and bias in their study design, it could not attribute the changes over time to the NR Strategy.

\section{Methods}

\section{Datasets and key variables}

Data

We investigate the effect of NR using two merged sources of longitudinal data, the Northern Ireland Household Panel Survey (NIHPS) and Understanding Society (details on the merging are provided in the Supplementary File). The NIHPS ran from 2001 to 2008 as an extension of the British Household Panel Survey (BHPS), which was replaced by Understanding Society in 2008. The first wave of the NIHPS achieved a sample of approximately 3,500 individuals from 2,000 households. Respondents in survey households aged sixteen years and over are interviewed annually in person. A continual twelve-year panel of the original sample respondents from 2001-2012 was constructed for this inquiry.

\section{Economic outcomes}

Current employment status was ascertained at the time of interview by participants selecting a response from a list of options. A dichotomous variable 'employment' was created as an outcome variable, coded one for 'self-employed' or 'in paid employment' and zero for all other options. The variable 'unemployed' was devised when the respondent reported being 'unemployed' and zero for all other options. Reported gross monthly household income was investigated as an outcome.

NI has higher welfare dependence than all other UK regions (Centre for Social Justice, 2010). Welfare dependency is particularly high in deprived areas. Therefore, we 
wished to investigate whether NR had an impact on dependency on state benefits.

Respondents reported the amount of monthly income they received from social benefits. We created a dichotomous outcome variable to indicate the respondent reported receiving state benefits. If income was reported from state benefits the outcome variable 'benefit receipt' was coded one, otherwise coded zero.

Respondents were asked how they were managing financially at the time of interview. A dichotomous variable representing 'experiencing financial difficulty' was fashioned, coded one where respondents reported they were finding it 'quite' or 'very difficult' as opposed to 'living comfortably', 'doing alright', 'just about getting by', coded zero.

\section{Hypotheses and Research Design}

\section{Hypotheses to be tested}

Policymakers hoped that efforts to economically revitalise intervention areas would lead to an improvement in the economic status of residents of assisted areas. However, as outlined above, the existing literature does not support this supposition and is, at best, inconclusive. Therefore, this study proposes to test two null hypotheses:

Hypothesis 1: There was no change in the economic outcomes - employment, unemployment, household income, benefits, subjective financial status - of residents in NRAs compared to the rest of NI as a result of NR.

Hypothesis 2: There was no change in the economic fortunes (as measured by five economic outcomes) between residents of NRAs and those in other similarly deprived areas of NI that did not received NR investment over the Strategy period. 


\section{Identification of intervention and control groups}

The location of survey respondents residence at the level of super output area (SOAs) was accessed for this study. SOAs represent small geographic areas in NI with an average population of 2,000. The NI Neighbourhood Information Service supplied best-fit small area geographies for the thirty-six NRAs which concord with SOAs. A dummy variable, NRA, was constructed which indicated whether a respondent resided in one of the thirty-six NRAs or not.

To address the first hypothesis, a control group of respondents residing in all SOAs in NI which did not fall into the delineated NRA SOA group was classified as the control group Non-NRAs. This comparison group permits a contrast of the results with the statutory evaluation. The second hypothesis required the identification of areas that were similarly deprived to NRAs but did not fall under the list of NRA SOAs. The 2005 NI Multiple Deprivation Measure ranked SOAs according to a composite measure of deprivation. A second control group that contained respondents living in the $25 \%$ most deprived SOAs that were not NRA SOAs was distinguished as our Analogous Control Narrow (ACN) group. To afford a larger comparison sample, a third control group that contained respondents living in the $30 \%$ most deprived SOAs was categorised as Analogous Control Wide (ACW). These similarly deprived comparison groups facilitate a greater 'like for like' comparison. The choice of similarly deprived geographies as controls has been a popular identification strategy for other ABI evaluations including NDC (Department for Communities and Local Government, 2010b; Stafford et al., 2014) and the Dutch District Approach (Droomers et al., 2016; Jongeneel-Grimen et al., 2016).

Despite our best identification efforts, we note at this point, the potential for unobservable factors to influence the results e.g. issues around the on-the-ground implementation of the policy, external and internal economic and political influences. 


\section{Difference-in-difference analysis}

Difference-in-difference is a quasi-experimental method by which the impact of a policy change on an outcome of interest can be inferred using observational data. NR presented a natural experiment where the designation of neighbourhoods for publicly funded regeneration was not random. Artificial control groups were fashioned to provide an understanding of the counterfactual of what would have occurred in NRAs had NR not been implemented. An advantage of DID is that it controls for non-random selection into treatment and control groups. Estimation of the difference in the change in the economic circumstances of respondents in NRAs relative to the controls before and after the NR Strategy permitted a test of the two null hypotheses.

\section{Equation estimated}

The economic outcome of interest is modelled as the dependent variable, $Y_{i t}$, which is the economic outcome of respondent $i$ at time $t$. Since the dependent variables are dichotomous they are modelled in a linear probability framework due to difficulties interpreting interaction terms in non-linear models (Athey and Imbens, 2006; Karaca-Mandic, Norton and Dowd, 2012):

$$
\begin{gathered}
Y_{i t}=\beta_{1} N R_{i t}+\beta_{2} S_{i t}+\beta_{3}\left(N R_{i t} * S_{i t}\right)+\beta_{4} X_{i t}+\alpha_{i}+\lambda_{t}+\varepsilon_{i t} \\
N R_{i t}= \begin{cases}0 & \text { Control group: Non NRAs, ACN }, A C W \\
1 & \text { NRA }\end{cases} \\
S_{i t}=\left\{\begin{array}{lll}
0 & \text { Pre NR } & (2001-2002) \\
1 & N R & (2003-2012)
\end{array}\right.
\end{gathered}
$$

Whether a survey respondent resided in a NR regenerative area or not when they were interviewed is represented as the dummy variable, $N R_{i t}$. Whether the survey response was 
given before or after the launch of the NR policy is represented as the dummy variable, $S_{i t}$. The coefficient on the interaction $N R_{i t}$ and $S_{i t}, \beta_{3}$, measures the difference-in-difference estimate of the effect of NR designation. Potential time variant confounders arising from the individual characteristics of respondents are represented by $X_{i t}$. These include education, marital status, number of children, self-rated health and mental health as explanatory variables. The time variance of these variables is documented in Table S-3 in the Supplementary File. Individual fixed effects in the panel are represented as $\alpha_{i}$; whilst, $\lambda_{t}$ captures time fixed effects, and $\varepsilon_{i t}$ is the idiosyncratic error term. Complete cases where respondents with complete information were analysed using STATA.

\section{$\underline{\text { Subgroup analysis }}$}

We wanted to investigate whether changes to disadvantaged neighbourhoods in NI brought about by the NR policy had different effects on economic welfare measures for different groups of the population. Some existing studies of urban regeneration policies have explored variances in economic consequences across gender (Romero and Noble, 2008; Escott and Buckner, 2013) and race (Pemberton et al., 2006). Our analysis is stratified by gender, the ethnic 'marker' of religion in NI (Catholic and Protestant - greater explained in the Supplementary File) and educational attainment (low qualifications - accomplished mandatory secondary education or lower).

\section{$\underline{\text { Parallel trends }}$}

Difference-in-difference estimation relies on the parallel trends assumption, where economic outcomes in the NR and control group(s) would follow the same time trend in the absence of NR. Where this assumption does not hold, estimates of the effect may be biased. There is no direct test of this assumption; however, a diagnostic indication of parallel trends can be 
explored. Regression on the economic dependent variable that includes the interaction of the pre-NR period and NR status, acts as an exploratory 'falsification' test for the validity of parallel trends. A limitation of our dataset is that the survey only began in 2001, two years prior to the intervention. Wave one (2001) is therefore the reference year, and investigating parallel trends is attempted by examining the statistical significance of the interaction between wave two and NR status - this should not be significant for the parallel trends assumption to hold.

The results of the 'falsification' test are provided in Table S-4 of the Supplementary File. These suggest that the assumption of parallel trends held for all models, with one exception - household income in the comparison with all non-NRAs. Thus, interpretations of the difference-in-difference coefficient on household income may be viewed with caution. Moreover, since a violation of parallel trends cannot be formally ruled out, based on a test of a single pre-treatment period, the potential for bias in the estimated effect remains. We add that graphically, parallel trends were also broadly suggested in the pre-NR trends in Figure 1, and there were no mean differences in the economic outcomes between the analogous controls before the policy, documented in Table S-2 in the Supplementary File.

\section{Robustness check}

A second post-intervention period for analysis was also investigated using data for 2006 onwards. While the policy was launched in 2003 , actions on the ground may have taken time to implement, resulting in lagged outcomes. 


\section{Results}

\section{Descriptive statistics}

Sample characteristics

Table 1 demonstrates that respondents from NRAs differed from those from the rest of NI across almost all characteristics. Respondents from NRAs had lower levels of educational attainment, differing marital status, more children, poorer self-rated health, greater mental distress, were more likely to be Catholic, unemployed, receiving benefits, finding it financially difficult and had lower levels of household income and employment. Respondents in analogous controls areas were not dissimilar to NRAs (confirmed in t-tests in Supplementary File Table S-2).

\section{Time trends in outcomes}

Employment was broadly unchanged in NRAs over the sample as illustrated in Figure 1; this was slightly dented by the international financial crisis / recession but subsequently recovered. Likewise, the proportions of respondents in employment were broadly stable in Non-NRAs, dipping during the recession and recovering. For the analogous control areas, the number of respondents in employment climbed prior to NR and remained relatively high in the early survey years but diminished after the years coinciding with the recession (survey wave eight and nine).

Unemployment was more volatile in NRAs in the later years of the survey. In NonNRAs, the early years of the survey saw declines in unemployment, but this trend reversed after survey wave eight, and remained relatively high post-recession. Unemployment in the analogously deprived controls decreased up to wave six, rose during the recession and shot up to NRA levels in the last wave of the survey. 
Gradual increases in household incomes for all study groups were observed. In NRAs benefit receipt was largely static over time, and there was a slight upturn in those receiving benefits in similarly distressed areas. The proportions reporting financial difficulties were slightly erratic for NRAs and deprived controls with a rise in the later survey years. There was also an increase in those reporting financial difficulties in wave's eight to twelve.

\section{Difference-in-difference results}

Table 2 shows that where standard errors are clustered on the individual panel unit, the employment difference between NRAs and Non-NRAs was not significant. For the period that coincided with the rollout of NR, no effect on employment was observed. The difference-in-difference estimate of the effect of NR on employment was null. NRAs and analogously disadvantaged areas did not have a differential employment rate. The differencein-difference estimate of the effect of NR on employment, while not significant, carried a negative sign, comparing NRAs to similarly deprived controls.

The probability of unemployment among respondents in NRAs, Non-NRAs and similarly deprived controls was not different in Table 2 . Though there was a reduction in unemployment during the Strategy rollout between NRAs and non-NRAs, the difference-indifference estimate of the effect of NR on unemployment was null.

Table 2 shows that household incomes in NRAs were lower than the non-policy areas of NI - in the unadjusted model the magnitude represented a $18.9 \%$ gap, adjusting for other explanatory variables the size of the gap attenuated to $16.8 \%$. Household incomes increased over the period in which the Strategy was operational. The difference-in-difference estimate of the effect of NR was positive but not statistically significant. Thus, NR did not reduce the gap in household incomes between NRAs and the rest of the region. There was no difference in household incomes between NRA respondents and the analogously disadvantaged 
controls. Despite the increase in household incomes over the Strategy period, the differencein-difference estimate of effect did not suggest a stimulus in household incomes from NR.

Table 2 shows that for the comparison of NRAs with the rest of NI and the similarly deprived controls, benefit receipt was slightly higher in NRAs, though this was not statistically significant. There was no effect of the NR policy on receipt of benefits over the policy period according to the difference-in-difference estimates.

There was no significant difference in those reporting financial difficulties in NRAs and the three control groups in Table 2. The estimated effect of NR on subjective economic welfare pointed to a minute reduction in those reporting difficulties, but this was statistically inconsequential across all three comparisons.

\section{Subgroup analysis}

There was limited evidence of differential effects of the NR policy across sub groups of the population (available on request). However, there was an estimated reduction of $4 \%$ in reporting difficult financial situations among Catholics in NRAs compared to Catholics in all policy-off areas. 
Table 1: Sample characteristics in 2001 (pre-intervention)

\begin{tabular}{|c|c|c|c|c|c|}
\hline \multicolumn{2}{|c|}{ Characteristics (\%) } & NRA & Non-NRA & $\mathrm{ACN}$ & ACW \\
\hline \multicolumn{2}{|l|}{$\mathrm{N}$} & 657 & 2280 & 212 & 320 \\
\hline \multicolumn{2}{|l|}{ Employment } & 34.9 & 48.0 & 34.9 & 34.4 \\
\hline \multicolumn{2}{|c|}{ Unemployment } & 8.7 & 3.9 & 8.5 & 6.6 \\
\hline \multicolumn{2}{|c|}{ Household income monthly ( $f$ mean) } & 1797 & 2397 & 1961 & 1858 \\
\hline \multicolumn{2}{|l|}{ Benefits } & 66.7 & 54.9 & 60.4 & 64.1 \\
\hline \multicolumn{2}{|c|}{ Financial difficulties } & 10.2 & 6.9 & 12.3 & 11.3 \\
\hline \multicolumn{2}{|l|}{ Female } & 61.3 & 57.2 & 57.1 & 58.1 \\
\hline \multicolumn{2}{|l|}{ Age } & 43.8 & 45.4 & 43.2 & 45.8 \\
\hline \multirow[t]{5}{*}{ Education } & Third level & 16.1 & 27.9 & 18.9 & 17.5 \\
\hline & Upper secondary (A Level) & 10.2 & 11.6 & 9.9 & 10.0 \\
\hline & Lower secondary (GCSE) & 21.5 & 20.5 & 21.2 & 19.4 \\
\hline & Other qualification & 9.3 & 10.9 & 9.0 & 9.1 \\
\hline & No qualifications & 42.9 & 29.0 & 41.0 & 44.1 \\
\hline \multirow[t]{4}{*}{ Marital status } & Single & 32.0 & 25.3 & 37.7 & 34.1 \\
\hline & Married/Civil Partnership & 48.6 & 60.1 & 42.9 & 46.3 \\
\hline & Separated/Divorced & 11.7 & 7.2 & 11.3 & 10.6 \\
\hline & Widowed & 7.8 & 7.4 & 8.0 & 9.1 \\
\hline \multicolumn{2}{|c|}{ Number of children (mean) } & 0.8 & 0.6 & 0.6 & 0.6 \\
\hline \multicolumn{2}{|c|}{ Good self-rated health } & 59.5 & 69.8 & 59.9 & 60.3 \\
\hline \multicolumn{2}{|c|}{ High mental distress score } & 7.3 & 4.0 & 6.1 & 5.3 \\
\hline \multirow[t]{3}{*}{ Religion } & Catholic & 55.6 & 34.3 & 56.1 & 49.1 \\
\hline & Protestant & 36.4 & 57.7 & 41.0 & 45.9 \\
\hline & Neither Catholic/Protestant & 4.9 & 3.7 & 0.5 & 2.3 \\
\hline
\end{tabular}


Figure 1: Economic outcomes 2001-2012 
Table 2: Difference-in-difference results

\begin{tabular}{|c|c|c|c|c|c|c|c|c|c|c|}
\hline & \multicolumn{2}{|c|}{ Employment } & \multicolumn{2}{|c|}{ Unemployment } & \multicolumn{2}{|c|}{ Household income } & \multicolumn{2}{|c|}{ Benefits } & \multicolumn{2}{|c|}{ Financially difficult } \\
\hline & (1) & $(2)$ & (1) & $(2)$ & (1) & $(2)$ & (1) & $(2)$ & (1) & $(2)$ \\
\hline \multicolumn{11}{|c|}{ 1. Comparison with Non NRAs $(n=4,055, N=22,687)$} \\
\hline \multirow{2}{*}{$\operatorname{NRA}\left(\beta_{1}\right)$} & -0.049 & -0.036 & -0.016 & -0.015 & $-0.189 * *$ & $-0.168 * *$ & 0.032 & 0.027 & -0.029 & -0.030 \\
\hline & $(0.038)$ & $(0.036)$ & $(0.018)$ & $(0.018)$ & $(0.061)$ & $(0.060)$ & $(0.029)$ & $(0.027)$ & $(0.021)$ & $(0.021)$ \\
\hline \multirow{2}{*}{ Strategy rollout $\left(\beta_{2}\right)$} & 0.003 & -0.004 & $-0.013^{* *}$ & $-0.014^{* *}$ & $0.112^{* * *}$ & $0.115^{* * *}$ & 0.006 & 0.006 & $-0.012^{+}$ & $-0.012^{+}$ \\
\hline & $(0.009)$ & $(0.009)$ & $(0.005)$ & $(0.005)$ & $(0.014)$ & $(0.014)$ & $(0.008)$ & $(0.008)$ & $(0.007)$ & $(0.007)$ \\
\hline $\begin{array}{l}\text { Difference-in-difference } \\
\left(\boldsymbol{\beta}_{3}\right)\end{array}$ & $\begin{array}{c}0.011 \\
(0.017)\end{array}$ & $\begin{array}{c}0.007 \\
(0.016)\end{array}$ & $\begin{array}{c}0.008 \\
(0.009)\end{array}$ & $\begin{array}{c}0.007 \\
(0.009)\end{array}$ & $\begin{array}{c}0.037 \\
(0.025)\end{array}$ & $\begin{array}{c}0.026 \\
(0.025)\end{array}$ & $\begin{array}{l}-0.000 \\
(0.016)\end{array}$ & $\begin{array}{c}0.007 \\
(0.016)\end{array}$ & $\begin{array}{l}-0.002 \\
(0.012)\end{array}$ & $\begin{array}{l}-0.003 \\
(0.012)\end{array}$ \\
\hline \multicolumn{11}{|c|}{ 2. Comparison with ACN $(n=1,286, N=6,363)$} \\
\hline \multirow{2}{*}{ NRA } & 0.066 & 0.063 & -0.123 & -0.121 & 0.199 & 0.230 & 0.086 & 0.088 & -0.040 & -0.047 \\
\hline & $(0.084)$ & $(0.081)$ & $(0.084)$ & $(0.084)$ & $(0.157)$ & (0.159) & $(0.073)$ & $(0.071)$ & $(0.066)$ & $(0.067)$ \\
\hline \multirow{2}{*}{ Strategy rollout } & $0.054^{+}$ & 0.046 & -0.033 & -0.034 & $0.146 * * *$ & $0.150 * * *$ & 0.004 & 0.010 & -0.003 & -0.006 \\
\hline & $(0.028)$ & $(0.028)$ & $(0.016)$ & $(0.016)$ & $(0.037)$ & $(0.037)$ & $(0.025)$ & $(0.025)$ & $(0.020)$ & $(0.020)$ \\
\hline \multirow{2}{*}{ Difference-in-difference } & -0.027 & -0.033 & 0.023 & 0.022 & -0.008 & -0.018 & -0.007 & -0.008 & -0.014 & -0.009 \\
\hline & $(0.031)$ & $(0.030)$ & $(0.017)$ & $(0.017)$ & $(0.045)$ & $(0.045)$ & $(0.029)$ & $(0.028)$ & $(0.021)$ & $(0.020)$ \\
\hline \multicolumn{11}{|c|}{ 3. Comparison with ACW $(n=1,452, N=7,145)$} \\
\hline \multirow{2}{*}{ NRA } & -0.011 & -0.011 & -0.065 & -0.063 & 0.101 & 0.101 & 0.072 & 0.066 & -0.015 & -0.014 \\
\hline & $(0.061)$ & $(0.058)$ & $(0.056)$ & $(0.056)$ & $(0.111)$ & $(0.111)$ & $(0.051)$ & $(0.051)$ & $(0.055)$ & $(0.057)$ \\
\hline \multirow{2}{*}{ Strategy rollout } & $0.049 *$ & $0.043^{+}$ & $-0.027^{+}$ & $-0.028^{*}$ & $0.139 * * *$ & $0.146 * * *$ & 0.001 & 0.003 & -0.014 & -0.015 \\
\hline & $(0.023)$ & $(0.023)$ & $(0.014)$ & $(0.014)$ & $(0.032)$ & $(0.033)$ & $(0.022)$ & $(0.021)$ & $(0.018)$ & $(0.018)$ \\
\hline \multirow{2}{*}{ Difference-in-difference } & -0.026 & -0.033 & 0.019 & 0.019 & -0.005 & -0.016 & -0.007 & -0.004 & -0.003 & -0.002 \\
\hline & $(0.026)$ & $(0.026)$ & $(0.014)$ & $(0.014)$ & $(0.040)$ & $(0.039)$ & $(0.026)$ & $(0.025)$ & $(0.019)$ & $(0.019)$ \\
\hline \multicolumn{11}{|c|}{$\begin{array}{l}\text { Model (1) is the basic difference-in-difference specification with fixed effects, time effects and no adjusted covariates. } \\
\text { Model (2) is model (1) adjusted for education, marital status, number of children, health status, mental distress. } \\
\text { ' } n \text { ': number of individuals, ' } N \text { ' number of observations (individual-time observations) } \\
\text { +Significant at } p<0.1 ;{ }^{*} \text { at } p<0.05 ; * * \text { at } p<0.01 * * * \text { at } p<0.001 \text {. Standard errors clustered on panel unit of individual (in parentheses). } \\
\text { Full results displayed in Table } S-7 \text { Supplementary file. }\end{array}$} \\
\hline
\end{tabular}


Robustness check

The results generated from where the cut off was set at 2006 corroborates the finding that NR did not provide an economic uplift for intervention areas (Supplementary Table S-6). 


\section{Discussion}

Difference-in-difference modelling reveals that there was no substantive change in employment, unemployment, household income, benefit receipt and subjective financial wellbeing between NRAs and all policy-off areas in NI over the course of the NR Strategy. The first null hypothesis that there was no change in the economic fortunes of residents in NRAs and the rest of NI as a result of NR cannot be rejected. The second null hypothesis also could not be rejected, since there was also no evidence of change in the economic welfare of residents in NRAs relative to other similarly deprived areas of NI that did not receive NR investment. It is however, possible that some individual NRAs did see improvements in these indicators, which may be masked by the aggregation of all NRAs as the treatment group.

On the contentious issue of religion in NI, we note that in wave one, survey respondents from NRAs were predominantly Catholic (55.6\%), with substantially less representation from the Protestant community (36.4\%). Commenting on the religious breakdown of the NRAs, Plöger (2007, p. 27) notes, 'A major political problem with the selection process was that the most disadvantaged areas were predominantly Catholic, whilst the next 10\% most deprived neighbourhoods were mostly Protestant and did not receive assistance'. The subgroup analysis did not demonstrate that one religious community benefitted from the policy more than another.

\section{Explaining the lack of economic uplift}

The potential of regeneration to achieve a reduction in economic inequalities was not successfully realised in the case of NR. The mix of schemes designed to provide training for those out of work, upgrade skills and provide employment space appear to have been ineffectual in improving economic circumstances at the population level. The 
policy contended with a prolonged economic recession in 2008-2009, which is likely to have limited the ability of beneficiaries of NR initiatives to realise their economic potential.

The recession also had consequences for public sector budgets from 2008 . Budget reductions and uncertainties may have affected the delivery of the programme where Partnerships could not afford to fund projects or when decisions on funding were delayed. The political environment was also unstable in NI. The NI Assembly was suspended for almost five years from October 2002, subject to direct rule from Westminster. Devolution was re-established in May 2007. The Review of Public Administration (Northern Ireland Assembly, 2009) also meant that future 'ownership' of NR lacked clarity for some of the rollout period. Furthermore, Knox (2016) commented that the financing of NR was disproportionately focused on supporting the costs of organisations funded by NR as opposed to delivering services.

Prior to the mid-term review, there was a lack of systematic monitoring of financial disbursements. However, with only $9.1 \%$ of the total budget invested in the economic renewal theme in $2012 / 13$, we speculate that there was too little investment to be a catalyst for change. The government evaluation reported that NRA Partnerships 'struggled to develop and implement meaningful projects' for economic renewal (RSM McClure Watters, 2014, p.77). NR is not unique in failing to create influential economic projects; Germany’s Social City was unsuccessful in implementing effective measures for entrepreneurship and employment (Weck, 2009). Weck (ibid, p.530) commented that 'While local economic development is seen to be an important issue, it seems that the questions of "how to start" and "what to do" seem to be difficult for local policymakers to resolve'. Additionally, Pearson and Lawless (2012) commented that NDC Partnerships in England implemented relatively few worklessness programmes, many of 
which were directed at those most distant from the labour market, and few led to substantial numbers moving into work. NDC per capita annual spend was over six times higher than that of NR yet the evaluations of NDC did not uncover improvements in economic indicators. Even where policies have implemented large-scale programmes to revitalise employment in urban locations, these have not always borne fruit (Levine, 1987; Church, 1988; Gomez, 1998; Barber and Hall, 2008).

Ongoing unresolved legacies of the conflict may also have curtailed the economic recovery of NRAs, which were affected by sporadic periods of social unrest due to dissident paramilitary activities and disputes over cultural events such as parades. The economic issues that characterise NI's most disadvantaged communities are complex, deeply rooted and intergenerational which are unlikely to be effectively combatted in the timeframe of a decade. However, it must also be acknowledged that realising the full impact of any regeneration initiative takes time and durability of impact can vary (Church, 1988; Tyler et al., 2013). Positive economic returns may manifest in the future from NR investment, such as those in education of younger generations. A narrowing of the gap in educational attainment between NRAs and the rest of NI was uncovered by RSM McClure Watters (2014). 


\section{Conclusions}

NR was the most ambitious, well-resourced area-based policy ever implemented in NI. This study is the first evaluation of NR to examine the effect of the policy on the reported economic situation of residents of areas undergoing regeneration, using the largest household panel survey in NI. The statistical techniques employed provide a more reliable estimate of the effect of the policy than those exploited by the government evaluation. The demographic and socio-economic information recorded for respondents permitted accounting for important contextual factors in estimating the impact of the policy on outcomes. Furthermore, the difference-in-difference design accounts for unobservable differences between the intervention and control groups.

Our analysis, and therefore our conclusions, are also subject to limitations of the dataset employed. There were only two pre-policy periods of data, which precluded a rigorous test, and hence, an unequivocal validation of the parallel trends assumption. Given this, there remains potential for bias in the estimates. Cognisant of these issues in empirical research, we advocate a cautious interpretation of the results. Additionally, since the data employed was from a secondary source, active participation in NR schemes designed to improve economic wellbeing of individuals was unknown. Therefore, it was not possible to investigate whether active involvement in NR activities resulted in a change to economic circumstances.

There has been a growing literature base evaluating the health effects of holistic urban regeneration policies in the academic sphere, but the economic effects of such policies have not been investigated to such an extent. Given that 'unemployment, worklessness and low income have been identified as the most potent causes of social exclusion and degeneration' (Pemberton et al. 2006, p.231), it is imperative that research investigates the effect of policy on economic circumstances. Since several 
area-based strategies have ceased operation it may also be interesting to explore whether the economic welfare of areas which were once assisted changes in the absence of government support, such as those for European funds (Becker, Egger and von Ehrlich, 2018).

NR did not achieve economic renewal in a decade in NI. However, the policy may have had a role in supporting residents of deprived communities during a challenging economic period. Achieving economic transformation in disadvantaged pockets of NI is likely to require sustained investment in education, cultural change to raise aspirations of individuals and communities, and strategies which address the underlying structural causes of economic disadvantage (McGregor and McConnachie, 1995; Carter, 2013). Policymakers in the UK, Europe and internationally must be realistic as to their expectations of the transformational capacity of ABIs in politically sensitive regions. There may also be a role for both public and private funders, such as local employers in training schemes, to ensure that sufficient resources are available to enable the effective implementation of interventions (McGregor and McConnachie, 1995; Steuerle and Jackson, 2016).

Significant policy challenges remain for deprived areas of NI despite NR efforts. In recent years, a divestment in large-scale, state-sponsored regeneration policies has occurred in the UK and other developed countries. The removal of regeneration from policy portfolios of national government may be merited where the effectiveness of the measures adopted has been limited. However, ABIs may remain necessary policy devices to prevent the further decline of blighted urban areas, though they have not proven sufficient solutions. 


\section{References}

Abadie, A. et al. (2010) 'Synthetic Control Methods for Comparative Case Studies: Estimating the Effect of California's Tobacco Control Program', Journal of the American Statistical Association, 105(490), pp. 493-505.

Accetturo, A. and de Blasio, G. (2012) 'Policies for local development: An evaluation of Italy's Patti Territoriali', Regional Science and Urban Economics. Elsevier B.V., 42(1-2), pp. 15-26.

Adair, A., Berry, J. and McGreal, S. (1996) 'Regeneration processes in Northern Ireland: The public sector and partnership structures', European Planning Studies, 4(5), pp. 527-543.

Athey, S. and Imbens, G. (2006) 'Identification and inference in nonlinear differencein-differences models', Econometrica, 74(2), pp. 431-497.

Barber, A. and Hall, S. (2008) 'Birmingham: whose urban renaissance? Regeneration as a response to economic restructuring', Policy Studies, 29(3), pp. 281-292.

Beatty, C. et al. (2010) 'Area-based regeneration partnerships and the role of central government: The New Deal for Communities programme in England', Policy \& Politics, 38(2), pp. 235-251.

Becker, S. O., Egger, P. and Von Ehrlich, M. (2013) 'Absorptive Capacity and the Growth and Investment Effects of Regional Transfers', American Economic Journal: Economic Policy, 5(4), pp. 29-77.

Becker, S. O., Egger, P. H. and von Ehrlich, M. (2010) 'Going NUTS: The effect of EU Structural Funds on regional performance', Journal of Public Economics, 94(9-10), pp. $578-590$.

Becker, S. O., Egger, P. H. and von Ehrlich, M. (2018) 'Effects of EU Regional Policy: 1989-2013', Regional Science and Urban Economics. Elsevier Ltd, 69(December 2017), pp. 143-152.

Boarnet, M. G. and Boagart, W. T. (1996) 'Enterprise Zones and Employment: Evidence from New Jersey', Journal of Urban Economics, 40, pp. 198-215.

Bondonio, D. and Engberg, J. (2000) 'Enterprise zones and local employment: Evidence from the states' programs', Regional Science and Urban Economics, 30(5), pp. 519- 
549.

Breen, R. (2000) 'Class Inequality and Social Mobility in Northern Ireland, 1973 to 1996', American Sociological Review, 65(3), pp. 392-406.

Busso, M., Gregory, J. and Kline, P. (2013) 'Assessing the incidence and efficiency of a prominent place based policy', American Economic Review, 103(2), pp. 897-947.

Cairns, E. and Darby, J. (1998) 'Conflict Theory and the Conflict in Northern Ireland', Conflict, 53(7), pp. 754-760.

Carter, D. (2013) 'Urban Regeneration, Digital Development Strategies and the Knowledge Economy: Manchester Case Study', Journal of the Knowledge Economy, 4(2), pp. 169-189.

Centre for Social Justice (2010) Breakthrough Northern Ireland, Secretary. London: The Centre for Social Justice.

Church, A. (1988) 'Urban regeneration in London Docklands: a five-year policy review', Environment and Planning C: Government and Policy, 6, pp. 187-208.

Cizkowicz, P. et al. (2017) 'The effects of special economic zones on employment and investment: A spatial panel modeling perspective', Journal of Economic Geography, 17(3), pp. 571-605.

Coulter, C. (2014) 'Under Which Constitutional Arrangement Would You Still Prefer to be Unemployed? Neoliberalism, the Peace Process, and the Politics of Class in Northern Ireland', Studies in Conflict \& Terrorism, 37(9), pp. 763-776.

Department for Communities and Local Government (2010a) The New Deal for Communities Experience: A final assessment, Communities. London: Department for Communities and Local Government.

Department for Communities and Local Government (2010b) The New Deal for Communities National Evaluation: Assessing impact and value for money. London: Department for Communities and Local Government.

Department for Communities and Neighbourhood Renewal Partnerships (2013) Neighbourhood Renewal Annual Reports. Available at: https://www.communitiesni.gov.uk/articles/resources-neighbourhood-renewal-partnerships (Accessed: 27 April 2017). 
Department for Social Development (2003) Neighbourhood Renewal - People and Place. Belfast: Department for Social Development.

Department for Social Development (2011) People and Place Renewal Mid-Term Review. Belfast: Department for Social Development.

Droomers, M. et al. (2016) 'The impact of intervening in green space in Dutch deprived neighbourhoods on physical activity and general health: results from the quasiexperimental URBAN40 study', Journal of Epidemiology and Community Health, 70, pp. 147-154.

Escott, K. and Buckner, L. (2013) ‘Improving employment and women’s well-being in regeneration programmes', International Journal of Public Sector Management, 26(3), pp. $250-263$.

European Commission (2010) Lisbon Strategy evaluation document. Brussels: European Commission.

Finnegan, M. (1998) 'Equity as a policy objective: the case of Northern Ireland', International Journal of Social Economics, 25(9), pp. 1367-1379.

Foden, M. et al. (2010) 'Linking interventions to outcomes in area regeneration', Town and Planning Review, 81(2), pp. 151-172.

Givord, P., Quantin, S. and Trevien, C. (2018) 'A long-term evaluation of the first generation of French urban enterprise zones', Journal of Urban Economics. Elsevier, 105(March 2015), pp. 149-161.

Gobillon, L., Magnac, T. and Selod, H. (2012) 'Do unemployed workers benefit from enterprise zones? The French experience', Journal of Public Economics. Elsevier B.V., 96(9-10), pp. 881-892.

Gomez, M. (1998) 'Reflective Images: The Case of Urban Regeneration in Glasgow and Bilbao', International Journal of Urban and Regional Research, 22(1), pp. 106121.

Greenbaum, R. and Engberg, J. (2000) 'An Evaluation of State Enterprise Zone Policies', Policy Studies Review, 17, pp. 29-46.

Ham, J. C. et al. (2011) 'Government programs can improve local labor markets: Evidence from State Enterprise Zones, Federal Empowerment Zones and Federal 
Enterprise Community', Journal of Public Economics, 95(7-8), pp. 779-797.

Jongeneel-Grimen, B. et al. (2016) 'Impact of a Dutch urban regeneration programme on mental health trends: a quasi-experimental study', Journal of Epidemiology and Community Health, 70, pp. 967-973.

Karaca-Mandic, P., Norton, E. C. and Dowd, B. (2012) 'Interaction Terms in Nonlinear Models', Health Services Research, 47(1), pp. 255-274.

Knox, C. (2016) 'Northern Ireland: where is the peace dividend?', Policy \& Politics, 44(3), pp. 485-503.

Levine, M. (1987) 'Downtown redevelopment as an urban growth strategy: A Critical Appraisal of the Baltimore Renaissance', Journal of Urban Affairs, 9(2).

Longo, A. and Alberini, A. (2006) 'What are the Effects of Contamination Risks on Commercial and Industrial Properties? Evidence from Baltimore, Maryland', Journal of Environmental Planning and Management, 49(5), pp. 713-737.

Mayer, T., Mayneris, F. and Py, L. (2015) 'The impact of Urban Enterprise Zones on establishment location decisions and labor market outcomes: evidence from France', Journal of Economic Geography, 17(October 2015), p. 1bv035-.

McCartney, G. et al. (2017) 'Regeneration and health: a structured, rapid literature review', Public Health. Elsevier Ltd, 148, pp. 69-87.

McGregor, A. and McConnachie, M. (1995) 'Social Exclusion, Urban Regeneration and Economic Reintegration', Urban Studies, 32(10), pp. 1587-1600.

McKittrick, D. et al. (1999) Lost Lives. Edinburgh: Edinburgh Mainstream.

Neumark, D. and Kolko, J. (2010) 'Do enterprise zones create jobs? Evidence from Califormia's enterprise zone program', Journal of Urban Economics, 68(1), pp. 1-19.

Neumark, D. and Simpson, H. (2015) 'Place-Based Policies', Handbook of Regional and Urban Economics.

O’Hearn, D. (2000) 'Peace Dividend, Foreign Investment, and Economic Regeneration: The Northern Irish Case', Social Problems, 47(2), pp. 180-200.

O’Hearn, D. (2008) 'How has Peace Changed the Northern Irish Political Economy?', Ethnopolitics, 7(1), pp. 101-118. 
O'Keefe, S. (2004) 'Job creation in California's enterprise zones: A comparison using a propensity score matching model', Journal of Urban Economics, 55(1), pp. 131-150.

Osborne, R. D. and Cormack, R. J. (1986) 'Unemployment and Religion in Northern Ireland', Economic and Social Review, 17(3), pp. 215-225.

Papke, L. (1994) 'Tax policy and urban development: Evidence from the Indiana enterprise zone program', Journal of Public Economics, 54(1), pp. 37-49.

Pearson, S. and Lawless, P. (2012) 'Population mobility in regeneration areas: Trends, drivers, and implications; evidence from England's New Deal for Communities Programme', Environment and Planning A, 44(8), pp. 2023-2039.

Pemberton, S. et al. (2006) 'Regeneration for all? Measuring and enhancing levels of Black and other raical minorities' economic activity', The International Journal of Sociology and Social Policy, 26(5/6), pp. 229-244.

Plöger, J. (2007) Belfast City Report. London: Centre for Analysis of Social Exclusion, London School of Economics and Political Science.

Raveaud, G. (2007) 'The European Employment Strategy: Towards More and Better Jobs?', Journal of Common Market Studies, 45(2), pp. 411-434.

Romero, R. G. (2009) 'Estimating the impact of England's area-based intervention "New Deal for Communities" on employment', Regional Science and Urban Economics. Elsevier B.V., 39(3), pp. 323-331.

Romero, R. G. and Noble, M. (2008) 'Evaluating England's “New Deal for Communities" programme using the difference-in-difference method', Journal of Economic Geography, 8(6), pp. 759-778.

RSM McClure Watters (2014) Neighbourhood Renewal A Final Evaluation. Belfast: Department for Social Development.

Stafford, M. et al. (2014) 'Evaluating the health inequalities impact of area-based initiatives across the socioeconomic spectrum: a controlled intervention study of the New Deal for Communities, 2002-2008.', Journal of Epidemiology and Community Health, 68(10), pp. 979-86.

Steuerle, E. and Jackson, L. (eds) (2016) 'Context Matters', in Advancing the Power of Economic Evidence to Inform Investments in Children, Youth, and Families. 
Washington, D.C.: National Acadmies Press.

The Portland Trust (2007) Economics in Peacemaking: Lessons from Northern Ireland. London: The Portland Trust.

Thomson, H. et al. (2006) 'Do urban regeneration programmes improve public health and reduce health inequalities? A synthesis of the evidence from UK policy and practice (1980-2004).', Journal of Epidemiology and Community Health, 60(2), pp. 108-115.

Tyler, P. et al. (2007) 'The Single Regeneration Budget: final evaluation', Communities and Local Government Publications.

Tyler, P. et al. (2013) 'Valuing the Benefits of Urban Regeneration', Urban Studies, 50(1), pp. 169-190.

Weck, S. (2009) 'Local Economic Development in Area-based Urban Regeneration in Germany', Local Economy, 24(6-7), pp. 523-535.

What Works Centre for Local Economic Growth (2016a) Evidence Review 10: Area Based Initiatives: Enterprise Zones.

What Works Centre for Local Economic Growth (2016b) 'Evidence Review 10: Area Based Initiatives: EU Programmes', (January).

Whyte, J. (1983) 'How much discrimination was there under the Unionist Regieme, 1921-1968', in Gallagher, T. and O’ Connell, J. (eds) Contemporary Irish Studies. Manchester: Manchester University Press, pp. 1-35.

Wilson, I. (2013) 'Outcomes for "stayers" in urban regeneration areas: The New Deal for Communities Programme in England', Urban Research and Practice, 6(2), pp. 174193. 